\title{
Fisiopatología de la sepsis por bacterias gram negativas: bases moleculares
}

Yardani Rafael Méndez Fandiño우 María Claudia Barrera C. ${ }^{2}$

1 Médico Internista, Epidemiólogo. MSc. Investigación Clínica yardanymendezf@yahoo.es, Docente Universidad Pedagógica y Tecnológica de Colombia.

2 Médico, Microbióloga industrial. Fundación Universitaria Juan N. Corpas. maria-barrera@juanncorpas.edu.co

Correspondencia: Dra. María Claudia Barrera maria-barrera@juanncorpas.edu.co

Como citar: Méndez YR, Barrera MC. Fisiopatología de la sepsis por bacterias gram negativas: bases moleculares. Cuarzo 2015; 21 (2): 88-103.

Recibido: 13 de agosto de 2015 Aceptado: 21 de octubre de 2015 Publicado: 15 de diciembre de 2015

Licencia creative commons (c) (i)

\section{Resumen}

La sepsis constituye un complejo síndrome en el que a consecuencia de una respuesta anómala del huésped frente a una infección se desencadenan una serie de mecanismos fisiopatológicos celulares y moleculares que se traducirán en el daño multiorgánico del paciente y su respectivas manifestaciones clínicas. Las bacterias gram negativas, gracias al lipopolisacárido (LPS), principal constituyente de su membrana externa son reconocidas por moléculas como la proteína de unión al lipopolisacàrido (LBP) y por complejos de receptores de membrana celular en el huésped que reconocen su estructura antigénica como son el TLR4, el CD14 y la MD2, dando lugar, por medio de diferentes vías de señalización mieloide dependiente (MyD88) y mieloide independiente o TRIF, a la activación de una serie de kinasas que finalmente a través de vías de señalización intracelular como como NF - kB, generarán cambios transcripcionales que inducirán la producción de citocinas pro inflamatorias, que explican el Síndrome de respuesta inflamatoria sistémica (SIRS) y las antinflamatorias, que explican el síndrome de repuesta anti inflamatorio compensatorio (CARS), ambos constituyen las fases de la sepsis a través de los cuales pasa el paciente séptico en diferentes momentos del proceso. Todos estos procesos fisiopatológicos moleculares de la sepsis son los que darán como resultado cambios en el endotelio, la microvasculatura, el sistema del complemento, la coagulación y finalmente en cada uno de los órganos del paciente las diferentes manifestaciones clínicas que desde scores de valoración del paciente, como el SOFA, permiten identificar al paciente en sepsis, su pronóstico y directrices acerca del tratamiento. Es así como la comprensión de las bases fisiopatológicas moleculares de las sepsis por gram negativos constituyen hoy en día la base para su definición, la comprensión de la clínica y el punto de partida para mejoras terapéuticas en el manejo de la sepsis, traducida en la supervivencia del paciente.

PALABRAS CLAVE: sepsis, bacterias gram-negativas, molecular, factores de virulencia, patología clínica. 


\section{Pathophysiology of sepsis by gram negative bacteria: Molecular bases}

Sepsis is a complex syndrome in which as a consequence of an abnormal response of the host against an infection, a series of cellular and molecular pathophysiological mechanisms are triggered, resulting in the multiorgan damage of the patient and their respective clinical manifestations. Gram-negative bacteria, due to the presence of lipopolysaccharide (LPS), the main constituent of its outer membrane, are recognized by molecules such as lipopolysaccharide binding protein (LBP) and complexes of cell membrane receptors in the host that recognize its structure Antigenic as are the TLR4, CD14 and MD2, giving rise, through different pathways of signaling dependent myeloid (MyD88) and independent myeloid or TRIF, to the activation of a series of kinases that finally through intracellular signaling pathways Such as NF - kB, will generate transcriptional changes that will induce the production of pro - inflammatory cytokines, which explain the Systemic Inflammatory Response Syndrome (SIRS) and the anti - inflammatory drugs that explain the compensatory anti inflammatory response syndrome (CARS) of the sepsis through which the septic patient passes in different moments of the process or. All these molecular pathophysiological processes of sepsis are those that will result in changes in the endothelium, the microvasculature, the complement system, the coagulation and finally in each one of the organs of the patient the different clinical manifestations that from scores of the patient's evaluation, such as the SOFA, identify the patient in sepsis, their prognosis and treatment guidelines. Thus, the understanding of the molecular pathophysiological bases of gram-negative sepsis is nowadays the basis for its definition, the understanding of the clinic and the starting point for therapeutic improvements in the management of sepsis, translated into survival of the patient.

KEYWORDS: sepsis, gram-negative bacteria, molecular, virulence factors, clinical pathology.

\section{Introducción}

La Sepsis constituye la segunda causa de mortalidad en unidades de cuidados intensivos no coronarios. Su incidencia, aunque no se conoce del todo, va en aumento, haciendo que sea un importante problema de salud pública que parece reflejar a una población con mayores comorbilidades y un mayor diagnóstico de la misma. Se estima que en las dos décadas pasadas tuvo un incremento anual del 9\% y para el 2013 llegó a afectar cerca de 240 por cada 100000 habitantes en los estados Unidos $(1,2)$.

Las primeras definiciones de Sepsis, establecidas por la Society of Critical Care Medicine (SCCM) en la conferencia consenso de 1991, se enfocaron en ésta como el resultado del Síndrome de Respuesta Inflamatoria Sistémica (SIRS) del huésped ante la infección; sin embargo para el 2014, la European Society of Intensive Care Medicine (ESICM) y SCCM la definen como una disfunción orgánica que pone en peligro la vida causada por una respuesta anómala del huésped ante la infección (1).

Esta nueva definición resulta de la comprensión y depuración de los conceptos de la fisiopatología, que a lo largo de estos años se ha llegado a tener. Este síndrome denominado sepsis, reconoce una respuesta inmune mul- tifacética, que incluye la activación de mecanismos pro $\mathrm{y}$ antiinflamatorios orientados a mantener la homeostasia del organismo en la defensa ante el agente causal de la infección. Las respuestas sistémicas no solo son inmunológicas; son hemodinámicas, ventilatorias, neuroendocrinas y metabólicas.

Las comorbilidades, el estado nutricional y los medicamentos administrados crónicamente modifican la fisiopatología y la semiología de los pacientes sépticos. Por otro lado los antígenos y endotoxinas bacterianas también son un elemento fuerte en el control de la respuesta inflamatoria sistémica (2). Las bacterias gram negativas son microorganismos que por décadas se han considerado los mayores causantes de sepsis bacteriana, sin embargo, en los últimos años, nuevamente cobran protagonismo el grupo de gram positivas, incrementando la tasa de resistencia a los antibióticos $(3,4)$.

Esta revisión narrativa sobre la fisiopatología de la sepsis por gram negativos desde una óptica molecular, pretende orientar al clínico hacia un enfoque funcional y más lógico en el tratamiento de la sepsis, que a su vez le permita entender las metas de la reanimación, controlar eficazmente la disfunción multiorgánica y prevenir la discapacidad del paciente séptico. 


\section{Bacterias Gram negativas: Estructura molecu- lar antigénica}

Los microorganismos gram negativos están en contacto permanente con el huésped y la pérdida del equilibrio ecológico dan lugar a la infección. La severidad de la misma depende de la respuesta del huésped, la capacidad antigénica del agente y el medio en el cual se desarrolla esta interfase. Los microorganismos desarrollan diversos factores de virulencia que les permiten protegerse y sobrevivir ante el sistema inmune del huésped, y les capacitan para atravesar las barreras mucosas, diseminarse y replicarse en diversos órganos. La eficacia de dichos factores se halla vinculada, entre muchos aspectos, a una serie de interacciones con componentes del citoesqueleto de las células del huésped como son los filamentos intermedios de vimentina, conduciendo a arreglos del citoesqueleto y a desencadenar diversas respuestas proinflamatorias $(2,5,6)$.

Dentro de estos factores de virulencia, los más importantes son las toxinas que podemos clasificarlas en tres tipos según su modo de acción (Tabla 1.), y según su naturaleza en exotoxinas, aquellas proteínas solubles y termolábiles que sintetizan las bacterias y liberan al exterior, y endotoxinas aquellas moléculas insertas en la membrana externa de las bacterias que solo se liberan tras la ruptura de la pared y cuyo mayor representante es el lipopolisacárido (LPS), presente de forma característica en las bacterias gram negativas (7).

El Lipopolisacarido (LPS), históricamente llamado endotoxina, es el mayor constituyente de la membrana celular externa de las bacterias gram negativas, llegan- do a ser considerado como el más fuerte desencadenante de la respuesta inflamatoria en humanos; aún a dosis tan bajas de $1 \mathrm{ng} / \mathrm{kg}$ masa corporal $/ \mathrm{h}$. El LPS corresponde a una molécula anfifílica, es decir que posee un dominio hidrofóbico que corresponde al Lípido A, el cual ancla el LPS a la membrana externa de la bacteria y un dominio hidrofílico correspondiente a una cubierta (Core) de oligosacáridos unidos por el ácido 3 - deoxy - D- manano - oct - ulosonico (Kdo) al lípido A y una región llamada antígeno $\mathrm{O}$ conocida como polisacárido específico $\mathrm{O}$. El LPS puede estar compuesto por estas tres regiones y en tal caso se llama forma suave (S) del LPS y en caso de no tener la región del polisacárido $\mathrm{O}$, se llama forma áspera (R) o LOS (Figura 1) $(7,8)$.

El Lípido A, está constituido por unidades del disacárido glucosamina unidas por enlaces $\beta$ (1-6), fosforiladas en la posición 1 y 4 del disacárido y unidas a ácidos grasos en la posición 2 y 3 de cada monosacárido, usualmente tiene 6 cadenas de ácidos grasos de diferente longitud, correspondientes en su mayoría al ácido capróico, láurico, mirístico, palmítico y esteárico. Cuando estas cadenas de ácidos grasos se unen directamente al azúcar se habla de cadenas primarias, si se unen por enlaces ester a los grupos hidroxilo de las cadenas primarias se llaman cadenas secundarias (Figura 2).

El lípido A corresponde a la región del LPS que es reconocida por la inmunidad innata, incluso a concentraciones picomolares puede ser suficiente para activar los macrófagos. Este se encuentra unido al dominio hidrofílico constituido por una región relativamente conservada de oligosacáridos y a la porción variable del O- polisacárido,

TABLA 1. Tipos de Enzimas bacterianas según su mecanismo de acción

\begin{tabular}{lll} 
Tipo & \multicolumn{1}{c}{ Características } & \multicolumn{1}{c}{ Ejemplo } \\
Tipo 1 & Rompen las células del huésped sin necesidad de entrar a la célula & Superantígenos de $S$. aureus y $S$ pyogenes. \\
Tipo 2 & $\begin{array}{l}\text { Destruyen las membranas de las células del huésped e invaden e } \\
\text { interrumpen los procesos de defensa del huésped dentro de la célula. }\end{array}$ & $\begin{array}{l}\text { Hemolisinas } \\
\text { Fosfolipasa }\end{array}$ \\
Tipo 3 & $\begin{array}{l}\text { Interrumpen las defensas del huésped y se diseminan a los órganos } \\
\text { cercanos. Son llamadas las Toxinas A/B. Estructura binaria, } \\
\text { el componente B se une a la superficie celular del huésped y el A } \\
\text { posee la actividad enzimática que daña la célula. }\end{array}$ & $\begin{array}{l}\text { Toxina Shiga Tel cólera } \\
\text { y toxina del antráx }\end{array}$ \\
\hline
\end{tabular}

Tomada de: 2. Ramachandran, G. Gram-positive and gram-negative bacterial toxins in sepsis A brief review. Virulence. 2014 Jan 1; 5(1): $213-218$. Disponible en: http://www.ncbi.nlm.nih.gov/pmc/articles/PMC3916377/ 


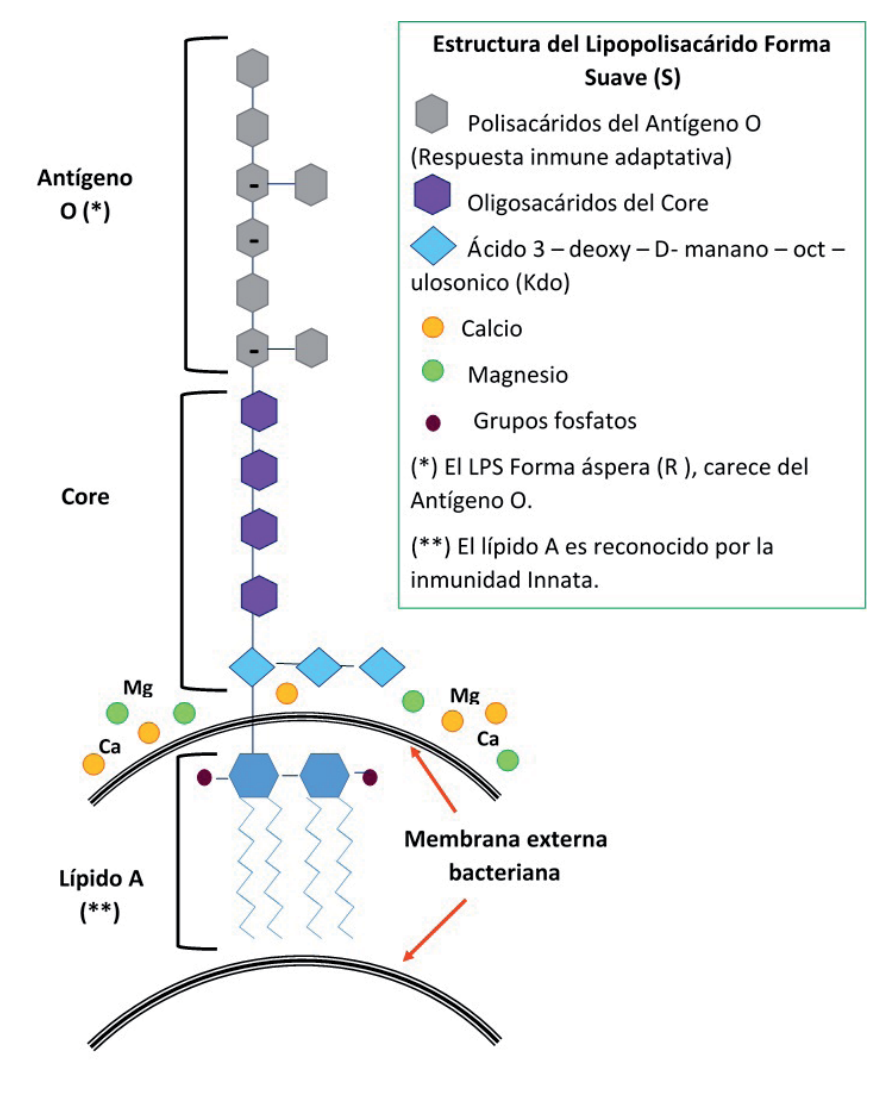

FIGURA 1. Estructura del LPS

Fuente: Construida por los autores con base en la hallada en el artículo: Steimle A, Autenrieth I, Frick J.S. Structure and function: Lipid A modifications in commensals and pathogens. Int. J. Med. Microbiol. 2016; 306(5):290-301.

la cual varía dependiendo de la especie bacteriana y está compuesta por un número de cero a cincuenta unidades repetitivas de oligosacáridos incluyendo 1 a 8 unidades con carga negativa que es neutralizada mediante iones divalentes de magnesio y calcio, presentes en la membrana externa bacteriana, lo cual asegura para la bacteria una efectiva barrera contra los antimicrobianos y otras moléculas nocivas. El O- polisacárido es la porción del LPS que activa la respuesta inmune adaptativa $(8,9)$.

Una vez la bacteria gram negativa infecta al huésped, el LPS se comporta como un patrón molecular asociado a patógenos (PMAPs), aquellas estructuras muy conservadas de los microorganismos invasores que son reconocidas por el sistema de inmunidad innato. La actividad del LPS como endotoxina depende, entre otros factores, de la asociación iónica que presente, así aquellos LPS ricos en sodio y potasio son mucho más activos como endotoxinas que aquellos con magnesio y calcio (9). En su papel fisiopatogénico de la sepsis el LPS también actúa como barrera ante el sistema inmunológico del huésped favoreciendo la colonización y explicando en algunos casos la resistencia bacteriana. Éste impide, en el marco de muchos otros mecanismos, la acción de lo que se han llamado los péptidos antimicrobianos catiónicos (CAMPs) dentro de los que se encuentra la polimixina, que logran desestabilizar la membrana celular bacteriana, inducen a la formación de poros llevando finalmente a la lisis celular. Su mecanismo de defensa bacteriana lo logra gracias a que las bacterias gram negativas, principal blanco de los CAMPs, adicionan moléculas con cargas positivas al lípido A, como con por ejemplo azúcares, tal es el caso de la aminoarabinosa en Pseudomonas aeuroginosa y Salmonella typhimurium; o residuos de aminoácidos en el caso de Vibrio cholerae, o fosfoetanolamina en el caso de Neisseria gonorrhoeae; que logran neutralizar la carca aniónica de sus superficie de membrana dada por los grupos fosfato del Lípido A, y con esto incrementan la resistencia a los CAMPs y su acción bactericida. En otros casos la resistencia a los CAMPs se da por remoción de las cargas negativas, aumentando la hidrofobicidad del LPS con lo que disminuye la permeabilidad de la membrana bacteriana impidiendo la inserción de los CAMPs (Figura 3) $(9,10)$.

Adicionalmente hoy en día se sabe que muchas bacterias cuentan con lo que se ha llamado el "quorum sensing", un mecanismo de comunicación bacteriano dado por enzimas que se activan ante altas densidades bacterianas mediante moléculas de comunicación o autoinductores (AI), producidas por las mismas bacterias que en el caso de las bacterias gram negativas están constituidas por moléculas denominadas AHLs (N-acyl L- hoserina lactones) que corresponden a moléculas cíclicas con cadenas simples de ácidos grasos, como las alquil quinolonas utilizadas por la $P$. aeuruginosa (Figura 4). Estas enzimas catalizan la síntesis de señales y receptores que reprograman la expresión de diversos genes entre estos los que codifican la síntesis de factores de virulencia, incluyendo el LPS, los mecanismos de resistencia antimicrobiana, moléculas que ejercen efectos sobre el sistema inmunitario del huésped, entre otros; asegurando con esto que una vez alcanzada la densidad de microorganismos necesaria, se produzca la cantidad de factores de virulencia y mecanismos sufi- 
cientes que permitan superar la inmunidad del huésped y resistir el ataque farmacológico. Dentro de las bacterias gram negativas en quien se ha identificado este sistema, están en Pseudomonas aeuroginosa, Escherichia coli y y Acinetobacter baumanii (11-14).

En el estudio y la comprensión de la estructura antigénica de las bacterias gram negativas, punto de partida de la fisiopatología de la sepsis, se reconoce la participación de una fuerte base genética que determina la expresión de los factores de virulencia. Dentro de esta regulación genética se ha identificado el papel de la proteína asociada a nucleoide (H - NS) la cual ha sido ampliamente estudiada en Escherichia coli y otras enterobacterias en las que juega un papel determinante en la estructura del nuceloide y modula le expresión de genes codificadores de la virulencia (15).

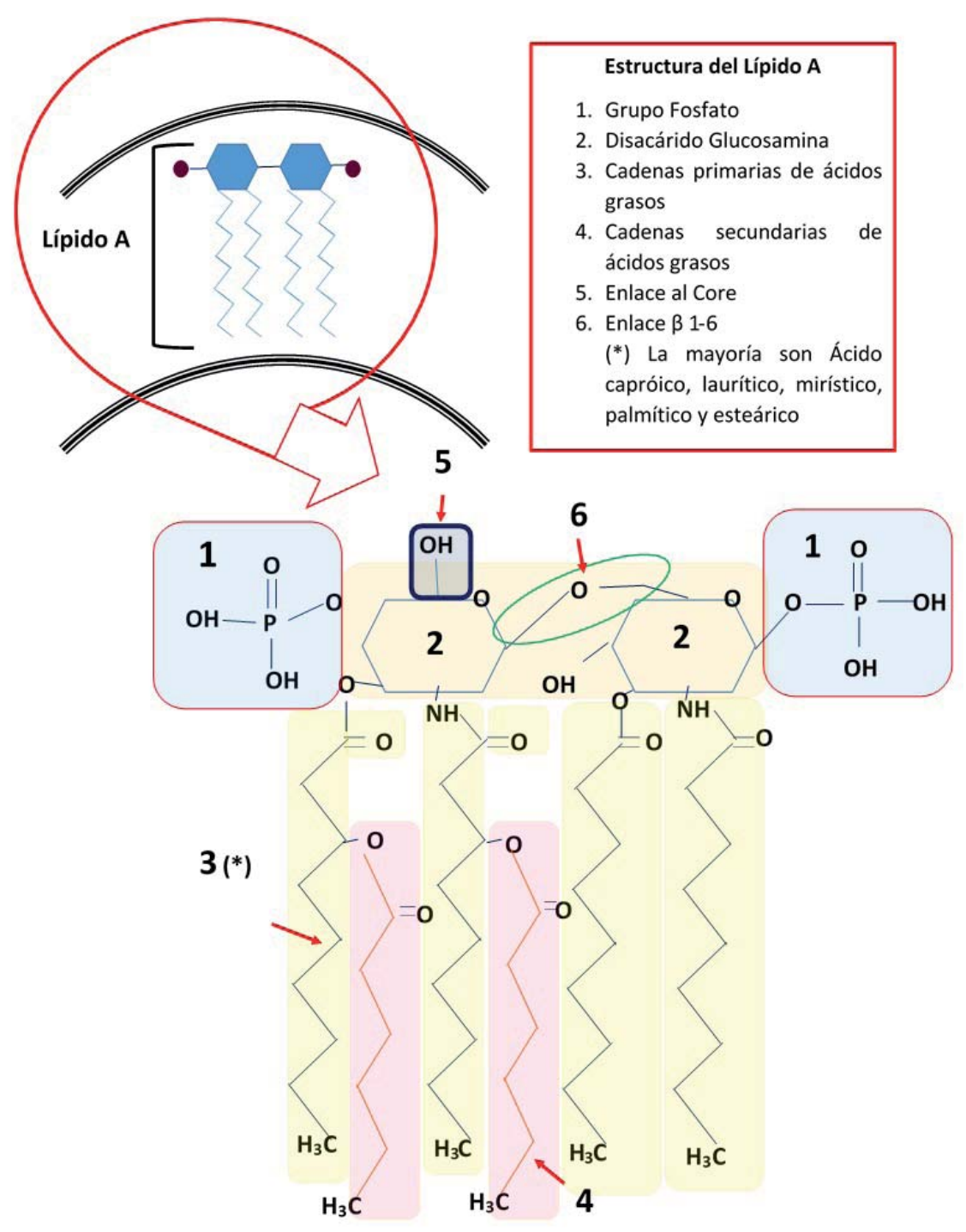

FIGURA 2. Estructura del Lípido A.

Fuente: Construida por los autores con base en la hallada en el artículo: Steimle A, Autenrieth I, Frick J.S. Structure and function: Lipid A modifications in commensals and pathogens. Int. J. Med. Microbiol. 2016; 306(5):290-301. 
Reconociendo la importancia del LPS en la fisiopatología de la sepsis, se han desarrollado una serie de medicamentos llamados antagonistas del lipopolisacáridos, dentro de los que se encuentran los péptidos sintéticos anti - lipopolisacárido (SALP), los cuales se postulan como candidatos para el tratamiento de la sepsis por gram negativos por mecanismos no bactericidas sino neutralizantes de las toxinas bacterianas que llevan a la respuesta inflamatoria $(16,17)$.
Dentro de éstos, que vienen siendo puestos a prueba en modelos animales, se encuentra la vizantina, glicolípido de la superficie celular de Corynebacterium spp, y las diferentes moléculas híbridas construidas a partir de esta; que compite con el lípido A en la unión a receptores de la inmunidad innata, específicamente el TLR - 4, pero a diferencia del lípido A, inhibe la producción de ciertas citoquinas proinflamatorias, entre estas el factor de necrosis tumoral alfa (TNF- $\alpha$ ) y la IL- $1 \beta$, ambos mediadores

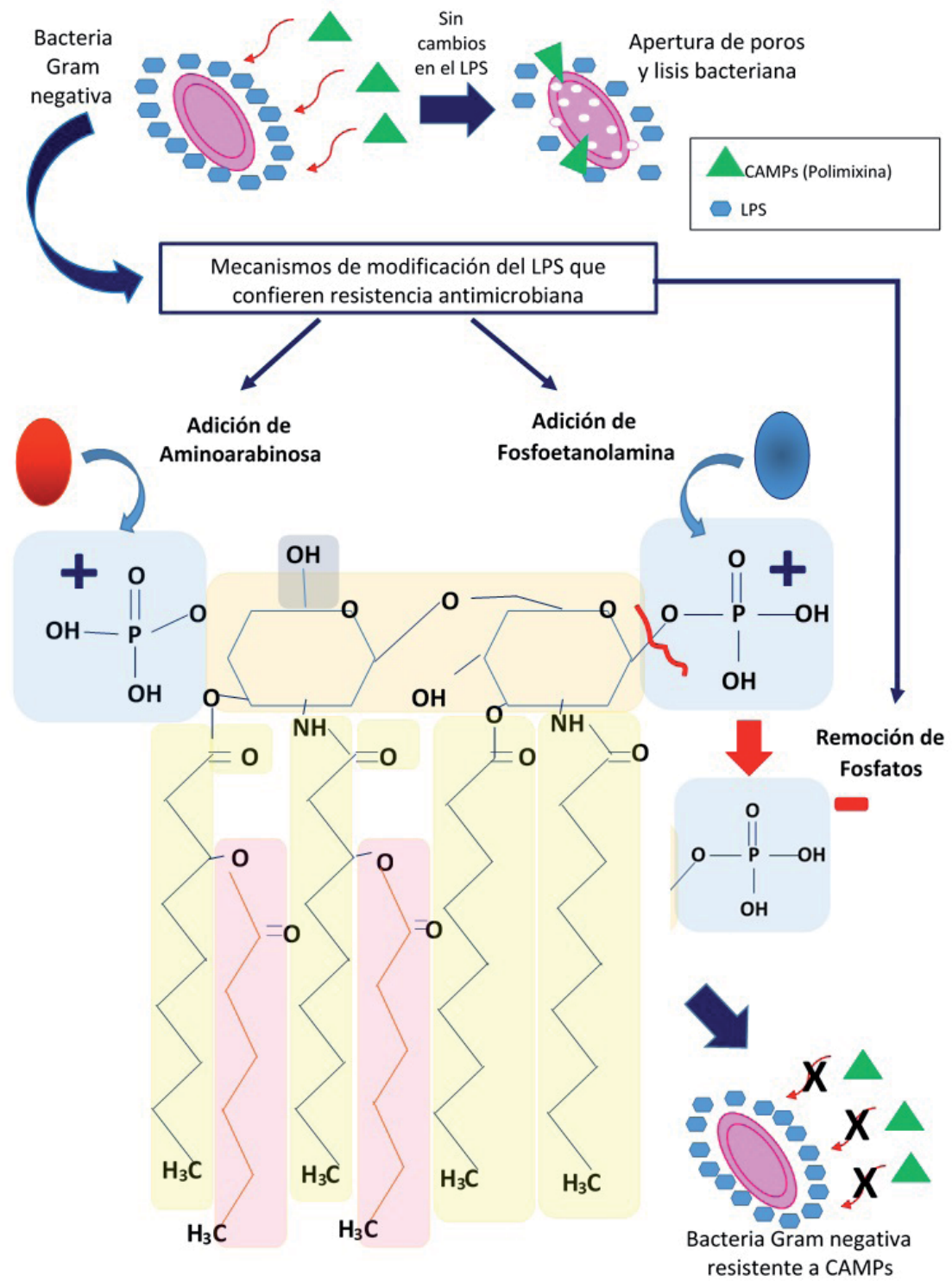

FIGURA 3. Péptidos antimicrobianos Catiónicos.

Fuente: Construida por los autores con base en la hallada en el artículo: Band V, Weiss D. Mechanisms of Antimicrobial Peptide Resistance in Gram-Negative Bacteria. Antibiotics. 2015;4:18-41. 


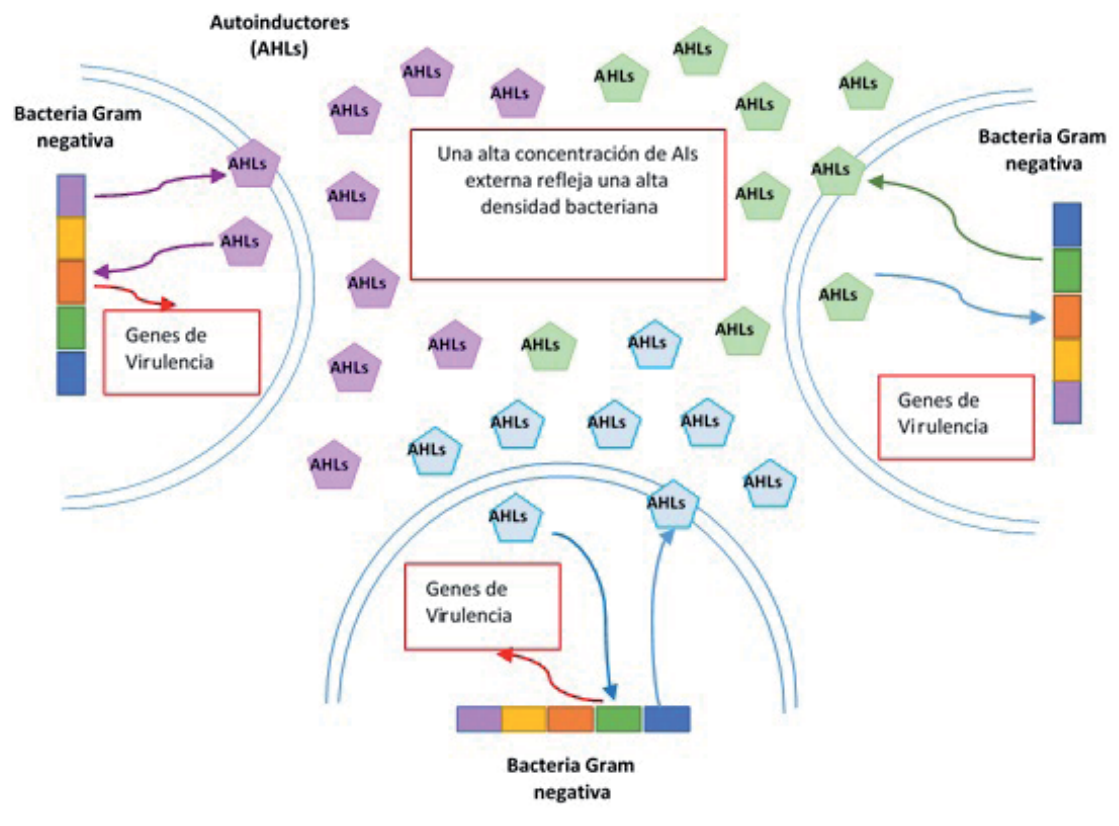

FIGURA 4. "Quorum sensing": Sistema de comunicación bacteriana.

Fuente: Construida por los autores con base en la hallada en el artículo: Reuter K, Steinbach A, Helms V. Interfering with Bacterial Quorum Sensing. Perspectives in Medicinal Chemistry 2016;8:1-15.

proinflamatorios efectores de la respuesta inmune inducida por los gram negativos en la sepsis. Un mecanismo idéntico como antagonista del lipopolisacárido se ha descrito y probado en modelos animales para el quercetín, principal flavonoide de las plantas y uno de los principales constituyentes de la dieta humana presente en frutas, verduras y bebidas (16-19).

\section{Identificación antigénica e Inicio de respuesta inmunológica: LBP, CD14, MD -2, Receptores TLR4 y señalización transcripcional}

Para que el LPS sea reconocido por el sistema inmune del huésped, debe ser removido de la membrana bacteriana. Esto ocurre indirectamente en células bacterianas muertas que llevan a la liberación del mismo o a través de la proteína de unión al lipopolisacárido (LBP). La LBP inicialmente fue descubierta como un reactante de fase aguda unido al LPS de la pared bacteriana formando el complejo LBP/LPS, posteriormente también se halló elevado en bacteremias por grampositivos (21). La LBP actúa como una transferasa y se considera un modulador po- tente del reconocimiento del LPS ya que puede remover moléculas desde la membrana bacteriana despolimerizando el LPS polimérico a monómeros que se unen a él y por intermedio de él al CD14 localizado en la superficie de macrófagos, monocitos y neutrófilos. La LBP adicionalmente se encuentra en el suero humano a concentraciones 5 a $10 \mu \mathrm{g} / \mathrm{ml}$ y es secretada en la luz intestinal donde identifica el LPS de las bacterias patógenas invasoras y las comensales que pueden ser simbióticas en el huésped y nunca inducirán enfermedad o patobiónticas que potencialmente pueden inducir reacciones inmunes patológicas. Dado el papel que desempeña la LBP, se considera que ayuda en el balance del sistema inmune intestinal y de otros epitelios y junto a la proteína bactericida que incrementa la permeabilidad (BPI) hacen parte de las proteínas de reconocimiento de patrones moleculares asociados a microorganismos que cumplen roles complementarios en la inmunidad innata. En casos de sepsis se ha hallado que la LBP incrementa sus niveles en $30-40 \mu \mathrm{g} / \mathrm{ml}$ en 24 horas casi 7 veces más de lo normal, sin embargo, continua en estudio su papel como marcador específico de sepsis $(8,21-23)$. 
Una vez se unen los fragmentos monoméricos de LPS y LBP se forma el complejo LBP/LPS, que se une al CD14, una glicoproteína unida a la membrana de monocitos, macrófagos, células dendríticas y en menor nivel en neutrófilos por un anclaje glicosil fosfatidil inositol sin dominio transmembrana; pero que igualmente puede estar en el medio extracelular en forma de proteína soluble. Para la transferencia del LPS al CD14 la albumina escuda la región hidrofóbica del lípido A. La CD14 transfiere el LPS monomérico a la proteína especializada en unir lípidos llamada factor de diferenciación mieloide 2 (MD - 2) que es una proteína soluble secretada al exterior de las células o que puede estar permanentemente unida al receptor TLR4 mediante puentes de hidrógeno dando origen al complejo protéico constituido por 2 moléculas de MD-2 y 2 moléculas de TLR4 (Figura 5) $(8,23,24)$.

El receptor TLR4, identificado como el receptor del LPS desde 1998, pertenece a los receptores similares a Toll (TLR), proteínas transmembrana de dominios extracelulares ricos en leucina y un dominio intracelular de cerca de 200 aminoácidos que contiene una región altamente conservada llamada dominio receptor Toll/IL - 1 (TIR) el cual se encarga de activar las cascadas de señalización intracelular. El ser humano cuenta con 10 tipos de receptores Toll diferentes, agrupados en dos tipos, transmembranales e intracelulares todos encargados del reconocimiento de los PAMPs en la inmunidad innata. El TLR4, pertenece a los transmembranales y a diferencia de otros TLR, no reconoce PAMPs aislados de ahí que su dominio externo reclute la MD-2 quien facilita la presentación del LPS. Tanto el TLR4 como el CD14, son codificados por genes cuyos polimorfismos regulan su expresión y se relacionan con una mayor o menor susceptibilidad a la sepsis $(11,25-27)$.

Una vez formado el complejo TLR4 - MD2 -LPS, se da inicio a la cascada de señalización transducción mediante el reclutamiento de 5 moléculas adaptadoras intracelulares, que darán lugar a dos vías de señalización: a) Vía de señalización mieloide dependiente en la que se recluta el factor de diferenciación mieloide 88 (MyD88), y b) Vía de señalización mieloide independiente o TRIF dependiente en la que se reclutan cuatro moléculas: TRIF (TIR-related adaptor protein inducing interferón), TRAM (TRIF-related adaptor molecule) y TIRAP (TIR domain containing adaptor protein), MAL (MyD88 adaptor like) y SARM (Sterile-alpha and Armadillo motif-containing Protein). Activadas estas vías de señalización se reclutan una serie de kinasas como son la IRAK 1- IRAK 4, TRAF 6 , TAK 1, que en conjunto llevarán, por la vía MyD88 dependiente a la activación de las vías de señalización $\mathrm{NF}-\mathrm{kB}$, cinasa c-Jun N- terminal, que activaran la transcripción de genes, más de 103 en total, codificadores de las citocinas proinflamatorias como el factor de necrosis tumoral alfa (TNF-a), la interleukin-6 (IL-6); y por la vía TRIF dependiente a activar el factor de transcripción IRF 3 que conducirá a la expresión de Interferones tipo I (IFN) y citosinas inducibles por INF como la IL - 10 y RANTES. Adicionalmente se aumentará la producción de radicales libres, anión superóxido, óxido nítrico, caspasas, formación del inflamosoma y producción péptidos antimicrobianos que paso a paso nos acercarán a la comprensión de la clínica manifiesta por el paciente que cursa con sepsis. (Figura 5) $(8,28,29)$.

En el marco de la activación de las citosinas proinflamatorias vía receptor TLR 4, han venido cobrando importancia otras moléculas que median una regulación negativa de la respuesta inflamatoria al actuar como moléculas que internalizan el receptor TLR4 y posteriormente lo reclutan en endosomas, esto conduce a una producción positiva de IL - 10 y a una regulación negativa de la actividad de la vía transcripcional del $\mathrm{NF}-\mathrm{kB}$ controlando al parecer la respuesta inmunológica ante el LPS en el huésped. Dentro de estas moléculas se encuentran las Anexinas, proteínas que se pueden unir a los fosfolípidos de membranas celulares a través del ión calcio y participar en mecanismos dinámicos que involucran la membrana celular como son la motilidad celular, endocitosis, fibrinólisis, formación de canales iónicos e interacciones de la matriz celular (30).

\section{Mediadores Químicos y disfunción sistémica: La fisiopatología explicando la clínica}

Como hemos visto, a lo largo de la fisiopatología de la sepsis, quienes modulan los efectos orgánicos y sistémicos evidentes en la clínica de la sepsis son mediadores químicos del tipo citocinas, proteínas inmunomoduladores que transmiten señales interceluares, y que según la acción que desencadenan en el cuerpo se agrupan en citocinas pro inflamatorias y citocinas antiinflamatorias. En el grupo de las pro inflamatorias encontramos TNF- $\alpha$, IL$1 \beta$, IL-2, IL-6, IL-8, and IFN- $\gamma$, y en el de las antinflamatorias encontramos principalmente la IL -10, el factor de crecimiento transformante beta (TGF)- $\beta$ e IL - 4 . El efecto conjunto del primer grupo de estas moléculas se traducirá 
en aumento de actividad fagocítica, lesión del endotelio vascular con aumento de permeabilidad capilar, síntesis de proteinas de fase aguda desde el hígado, quimiotaxis de leucocitos a sitios de infección e inflamación, activación del sistema de complemento, activación del sistema de la coagulación; por su parte el efecto de las moléculas antiinflamatorias generará una disminución marcada de producción de citocinas pro inflamatorias por parte de los monocitos, específicamente TNF- $\alpha$, IL- $1 \beta$, and IL-6, suscitándose el inicio de lo que se ha llamado el Síndrome de

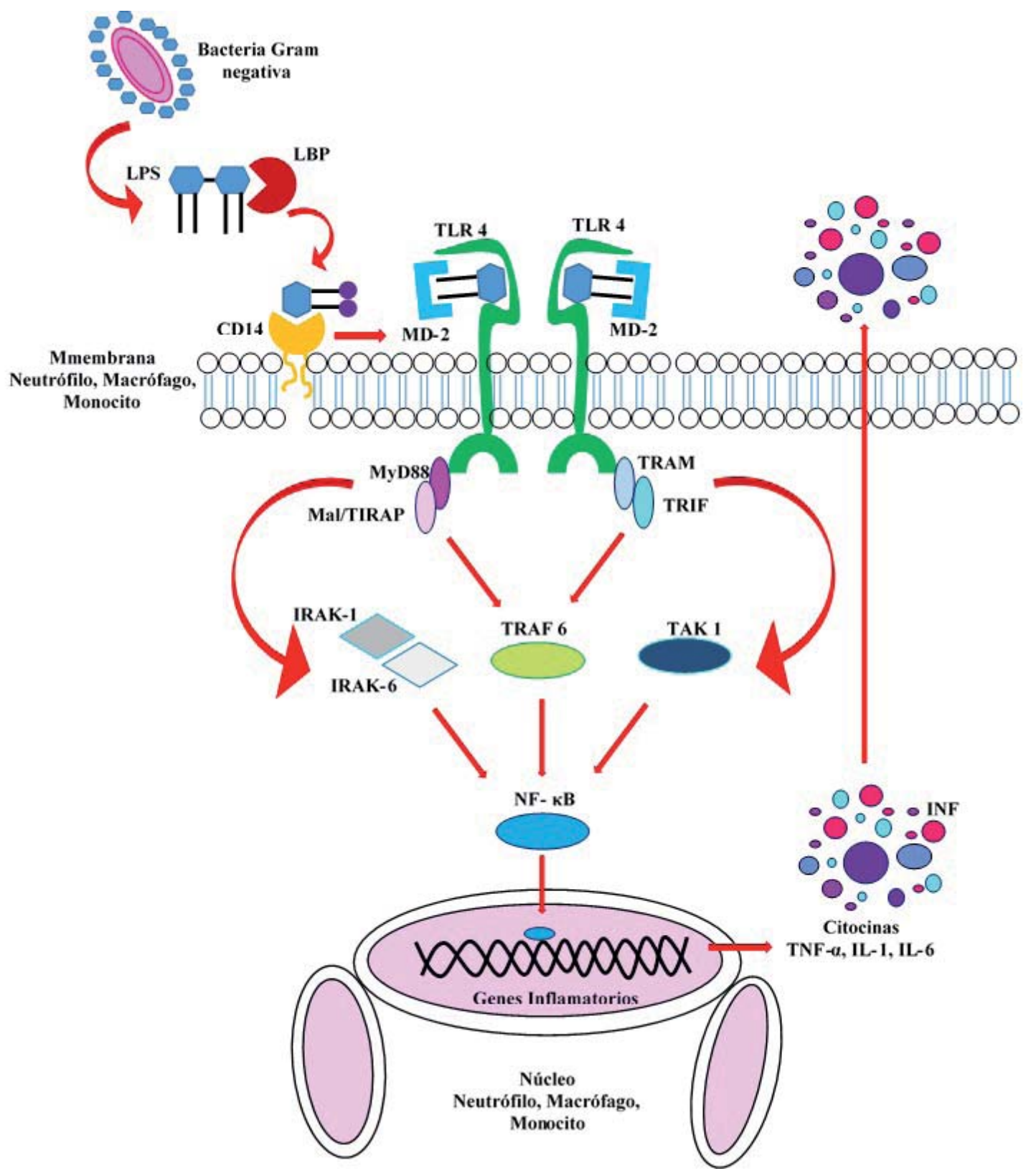

FIGURA 5. Formación del complejo LPS/LBP unión al CD4, transferencia al MD-2, formación del complejo MD-2/LPS//TLR4 y activación de señales transcripcionales

Fuente: Construida por los autores con base en la hallada en el artículo: Płóciennikowska A, Hromada-Judycka A, Borzecka K, Kwiatkowska K. Co-operation of TLR4 and raft proteins in LPS-induced pro-inflammatory signaling. Cell. Mol. Life Sci. 2015;72:557-581 
repuesta anti inflamatorio compensatorio (CARS) o parálisis inmune caracterizado por apoptosis de linfocitos, disminución de moléculas MHC clase II en monocitos / macrófagos, disminución de la función de linfocitos y fagocitos. Para este último no existe terapéutica que pueda combatirlo y los pacientes que llegan al CARS normalmente exhiben síndromes típicos que siguen a la reacción SIRS - CARS como son el síndrome de catabolismo persistente de inflamación - inmunosupresión (PICS) y el síndrome de disfunción multiorgánica (MODS) $(37,40,47)$.

Dentro de las citocinas involucradas en la sepsis, el TNF- $\alpha$ y la IL -1, son las más ampliamente estudiadas, se les ha llamado las citocinas primarias de la sepsis, juntas actúan sinérgicamente en los hallazgos fisiopatológicos de permeabilidad vascular, edema pulmonar y hemorragia característicos del shock, y se consideran citocinas pirogénicas que amplifican la cascada inflamatoria en forma autocrina y paracrina al activar macrófagos para secretar otras citocinas pro inflamatorias (Il-6, IL -8 y MIF), oxígeno reactivo y especies reactivas. El papel de estas citocinas en la pro inflamación está dado por el balance entre sus concentraciones y la de los antagonistas de sus receptores conocidos como TNFRs, IL -1R2 e IL - 1Ra. La IL -6 por su parte es responsable de la respuesta de fase aguda que incluye fiebre, leucocitosis, liberación de reactantes de fase aguda como PCR, componentes del complemento, fibrinógeno y ferritina, esta también promueve la respuesta antiinflamatoria al inhibir la liberación del TNF- $\alpha$ y la IL -1 y eleva niveles de antiinflamatorios como cortisol, IL - 10 y antagonistas de los receptores del TNF- $\alpha$ y la IL -1 . La IL -12 se encarga de activar la respuesta inmune adaptativa tipo 1 caracterizada por respuestas fagocíticas mononucleares, induce a las células $\mathrm{T}$ y los natural killer a producir IFN- $\gamma$ que activa los macrófagos y además incrementa la proliferación y formación de progenitores hematopoyéticos. El MIF, factor inhibitorio de migración de macrófagos, una citocina pro inflamatoria pleiotrópica que es liberada de las células pituitarias en respuesta al LPS y al estrés, así como de monocitos, macrófagos y adicionalmente aunque en menor cantidad por células endoteliales y epiteliales; ésta genera incremento de la supervivencia de los macrófagos, de la expresión de TLR4, del reclutamiento de éstos, de la secreción de otras citocinas, se considera un mediador importante de la disfunción miocárdica inducida por LPS y un predictor temprano de supervivencia en pacientes con sepsis. La IL - 10, una de las citocinas anti - inflamatorias, exhibe numerosas funciones que suprimen la respuesta inflamatoria y la han llevado a ser considera como protectora en patologías inducidas por el LPS. Dentro de sus funciones se encuentran: suprimir la producción de mediadores pro inflamatorios mencionados, estimula la producción de antagonistas de los receptores de TNF- $\alpha$ e IL-1. El TGF- $\beta$ inhibe la liberación de mediadores pros inflamatorios incluyendo la HMGB1, estimula igualmente la producción de antagonistas de receptores de TNF- $\alpha$ e IL-1, inhibe las funciones de los linfocitos $\mathrm{T}$ y se le ha vinculado en el fenómeno de tolerancia al LPS exhibido por monocitos y macrófagos característico de una respuesta disminuida de citocinas secundaria a cambios en el LPS. Las funciones de estas citocinas se resumen en la Tabla $2(37,48)$.

Al comprender las funciones de cada uno de estas citocinas y sus efectores finales, podemos acercarnos a la comprensión de los efectos sistémicos que se observan en el paciente séptico. De acuerdo al tercer consenso Internacional de definiciones para Sepsis realizado en el 2014, al momento de identificar criterios clínicos que nos permitan identificar un paciente con sepsis, se deben tomar como punto de partida un cambio en el score de SOFA (Sequential [Sepsis-Related] Organ Failure Assessment) igual o mayor a 2 puntos luego de que se ha presentado la infección. Este score se base en parámetros netamente clínicos como son la respiración evaluada a través de la PAFI ( $\mathrm{PaO} 2 / \mathrm{FiO} 2)$, coagulación, función hepática medida por valor de Bilirrubina, parámetro cardiovascular de tensión arterial, parámetro del sistema nervioso central, escala de glasgow; y parámetro de función renal, creatinina o flujo urinario. Cada uno de estos parámetros evalúa uno de los sistemas comprometidos en falla multiórganica característica de la sepsis, y en paralelo diseñaron los criterios quick SOFA basados en una frecuencia respiratoria mayor a $22 \mathrm{rpm}$, alteración mental con Glasgow menor a 13 y presión sistólica menor a $100 \mathrm{~mm} \mathrm{Hg}$, que en caso de cumplirse 2 de tres de estos criterios lleva a pensar en pacientes en quienes se debe buscar la disfunción orgánica, iniciar o escalar a la terapia más apropiada, considerar cuidado crítico o incrementar la frecuencia de monitorización (1).

En la base de cada uno de los hallazgos clínicos del SOFA, se encuentra lo que cada una de las etapas de la fisiopatología de la sepsis ocasiona a nivel celular, endotelial, circulatorio y metabólico en los diferentes sistemas del cuerpo del paciente, así el hígado, uno de los órganos evaluados en el SOFA, se comporta como un órgano lin- 
foide en la sepsis al ser encargado de procesos de respuesta inmune directa como son la eliminación de las toxinas bacterianas y bacterias, a través de mediante la activación de las células de la inmunidad presentes en él: las células endoteliales sinusoidales y de kupffer, siendo esas últimas responsables de producir citocinas proinflamatorias TNF- $\alpha$, IL-1, IL-6, interferón gamma (IFN- $\gamma$ ), IL-8, radicales libres y NO. En su papel de órgano linfoide, los hepatocitos y las células estrelladas participan como células presentadoras de antígenos a través de receptores TLR lo que lleva a que recluten numerosos neutrófilos, CD4, CD8, Natural Killer hepáticos y se desencadenen los me- canismos moleculares mencionados. Adicional a su papel activo en la respuesta inflamatoria este es el blanco de muchas de las citocinas proinflamatorias como el TNF $-\alpha$ y la IL - 6 que inducen la producción de reactantes de fase aguda en él como es la PCR, activan sistemas de coagulación, y específicamente en el hígado inhiben la excreción de bilirrubina conjugada dando lugar a hiperbilirrubinemia indirecta y su respectiva manifestación sintomática de ictericia. En el contexto del proceso inflamatorio, de piroptosis y apoptosis que ocurre en la sepsis, se generan lesiones hepáticas que incluyen inflamación portal, necrosis centrolobular, inflamación lobular, apoptosis hepato-

TABLA 2. Función de las Citocinas pro inflamatorias y anti inflamatorias involucradas en la sepsis.

Citocinas proinflamatorias
Citocinas
Células que las producen
Funciones

\begin{tabular}{|c|c|c|}
\hline TNF- $\alpha$ & $\begin{array}{l}\text { Macrófagos activados (Principalmente por LPS), } \\
\text { linfocitos y fibroblastos }\end{array}$ & $\begin{array}{l}\text { "Regulador master" de producción de citocinas } \\
\text { inflamatorias, expresión en células endoteliales de } \\
\text { moléculas de adhesión intercelular (ICAM - 1), moléculas } \\
\text { de adhesión vascular (VCAM - 1); activación de } \\
\text { neutrófilos, eosinófilos y monocitos; Producción de más } \\
\text { citocinas (IL -1 e IL - 6), pirógeno endógeno; Inducción } \\
\text { de producción de reactantes de fase aguda; activa el sistema } \\
\text { de coagulación; suprime la división celular en la médula } \\
\text { ósea dando linfopenia e inmunodeficiencia; caquexia al } \\
\text { suprimir el apetito; apoptosis }\end{array}$ \\
\hline IL - 1 & $\begin{array}{l}\text { Macrófagos activados (Principalmente por LPS), } \\
\text { linfocitos y fibroblastos }\end{array}$ & $\begin{array}{l}\text { Pirógeno endógeno, activa la coagulación, estimula la hematopoyesis } \\
\text { promueve la extravasación de células inflamatorias }\end{array}$ \\
\hline IL - 6 & $\begin{array}{l}\text { Macrófagos activados (Principalmente por LPS), } \\
\text { linfocitos y fibroblastos }\end{array}$ & $\begin{array}{l}\text { Activa linfocitos B y linfocitos T, modula la hematopoyesis; } \\
\text { el mayor mediador de respuesta de fase aguda. }\end{array}$ \\
\hline MIF & $\begin{array}{l}\text { Células pituitarias, monocitos/macrófagos } \\
\text { los efectos anti inflamatorios de los glucocorticoides }\end{array}$ & Activación de macrófagos y células $\mathrm{T}$, anula la respuesta de \\
\hline
\end{tabular}

Citocinas Anti - inflamatorias

Citocinas

IL $-10 \quad$ Células inmunes del sistema inmune adaptativo e innatos

TGF- $\beta$ Macrófagos, células de músculo liso

IL - 4 Linfocitos Th 2, mastocitos, basófilos eosinófilos

\section{Funciones}

Propiedades inmunosupresivas como bloqueo de presentación de antígenos y fagocitosis

Involucrado en reparación tisular, fibrosis, inmunosupresión inducida por sepsis

Promueve la diferenciación de linfocitos Th2

Tomada de: Bloos F, Reinhart K. Virulence. 2014 Jan 1;5(1):154-60. 
celular, colangitis y esteatosis, se encuentra la elevación de la bilirrubina mencionada y de la fosfatasa alcalina en fases tempranas y en fases tardía de transaminasas. $\mathrm{Su}$ doble papel en la eliminación de los antígenos pero a la vez ser productor de muchas de las moléculas de la inflamación, hacen que en la sepsis se genere un daño directo sobre él y a la vez que él favorezca el daño en otros órganos como el pulmón, que se verá afectado por la excesiva producción de citocinas y NO dando lugar al síndrome de dificultad respiratoria agudo que puede llevar a falla respiratoria de ahí que sea evaluado en el SOFA a través del primer parámetro de la PAFI y en el SOFA a través de la frecuencia respiratoria $(49,50)$.

En la comprensión de las manifestaciones clínicas de la sepsis desde la fisiopatología, encontramos que en la respuesta inmune innata, los neutrófilos, reconocidos como células fagocíticas, juegan el papel de proteger al huésped en la sepsis al encargarse de eliminar los microorganismos vía fagocitosis, en la que la producción del NO es determinante; degranulación, o formación de trampas extracelulares de neutrófilos (NETs). Adicionalmente, cuentan con receptores que reconocen PAMPs dando lugar al inicio cascadas de señalización para generar la respuesta ante el patógeno Sin embargo durante la sepsis la respuesta inflamatoria sistémica genera la activación de neutrófilos presentes en la circulación, dando lugar a obstrucción de capilares y posterior isquemia de tejidos. Estas células igualmente pueden migrar a órganos vitales, al parecer gracias a la expresión de un grupo de receptores en su superficie llamados CCR2, que no median el reclutamiento de estas células en el sitio de la infección, pero si median su infiltración en órganos vitales como pulmón en el que se da una excesiva activación de neutrófilos y en donde estas células liberan factores de lisis y citocinas proinflamatorias que van a contribuir al daño del mismo. La hipoperfusión y la hipoxia tisular que caracteriza la lesión orgánica en la sepsis, se ha atribuido a la oclusión por neutrófilos de la microcirculación, a la lesión endotelial generada por las citocinas producidas en el proceso de respuesta inmune ante la infección que en conjunto dan lugar a un perfil trombogénico que favorecerá la coagulación intravascular. Adicionalmente en estados de sepsis severa, según estudios en modelos animales, los receptores que participan en la quimiotaxis de los neutrófilos al lugar de la infección, llamados CXCR2 que responden a quimioatrayentes como el CXCL2, disminuyen, al parecer por una desensibilización e internalización de los mismos una vez se activa el TLR por los PAMPs bacterianos y ante la generación de citocinas proinflamatorias como TNF $\alpha$ y NO, afectándose así la migración de los neutrófilos y con esto el crecimiento descontrolado de las bacterias, la activación excesiva de los mismos con largas supervivencias y agudizando la lesión vascular y orgánica descrita (Figura 6) $(11,44,51)$.

La inflamación y la coagulación están interconectadas generando el proceso que se ha llamado inmunotrombosis, de ahí que, sumado al efecto sobre el sistema del complemento, en la sepsis se presenta disregulación de la cascada de la coagulación al punto que la inflamación descontrolada puede promover coagulación intravascular diseminada (DIC). Varios elementos de la coagulación participan en la amplificación de la respuesta inflamatoria, por ejemplo, las plaquetas reconocen PAMPs y DAMPs mediante los receptores TLR4 expuestos en su superficie y al hacerlo son capaces de presentar los microorganismos y antígenos a los neutrófilos dando lugar a la respuesta inmune mediada por ellos ya descrita (52).

Ahora bien, la DIC, considerada como el más importante marcador de pobre pronóstico en sepsis, se caracteriza por una masiva producción de trombina, acelerado consumo activación de plaquetas, deterioro de la fibrinólisis y trombosis microvascular, lo cual es originado en la sepsis a través de la generación de factor tisular mediador de trombina o factor tisular intravascular (TF), disminución de mecanismos anticoagulantes como son la antitrombina (AT), proteína C activada (APC) y el factor tisular inhibidor (TFPI); y daño de la fibrinólisis. El TF, producido en monocitos, leucocitos, plaquetas y células endoteliales, bajo la acción de citocinas proinflamatorias como el TNF- $\alpha$ y la IL - 1 y la HMGB1, parece ser la llave que conecta la sepsis con la coagulación. La sangre queda expuesta al TF de dos maneras, una cuando se genera una lesión endotelial que permite que sea expuesta a células extravasculares que expresan el TF, y otra en la que se expone a monocitos, leucocitos y neutrófilos circulantes activados en la inflamación que lo exponen en su superficie. El TF activa la coagulación a través del factor VIIa, al cual se une formando el complejo TF - VIIa que activa la trombina que lleva el fibrinógeno a fibrina en un proceso conocido como hipercoagulabilidad, y en paralelo genera agregación plaquetaria. Su principal inhibidor es el TFPI, el cual al igual que el inhibidor del activador del plasminógeno (PAI -1), la antitrombina III, el inhibidor de 
la fibrinólisis activable por trombina (TAFI) y, la proteína $\mathrm{C}$, hacen parte de los mecanismos anticoagulantes que se ven reducidos en la sepsis por varios mecanismos, disminución de su síntesis, incremento del consumo y degradación de los mismos por proteasas como la plasmina. La antitrombina, principal mecanismo anticoagulante, tiene la habilidad de inhibir la señal de activación que ejerce el LPS sobre los macrófagos disminuyendo así el nivel de inflamación, adicionalmente actúa compitiendo con los patógenos bacterianos uniéndose a los sitios de unión en las superficies endoteliales previniendo el daño endotelial generado por los mismos, dado el impacto de su función en el mantenimiento de la homeostasis de la inflamación y la coagulación, la reducción de su actividad es proporcional a la severidad de la sepsis, la falla orgánica y la DIC. La Proteína $C$ es activada en condiciones normales, por la trombina unida a la trombomodulina y por el receptor endotelial de la proteína C (EPCR) en las células endoteliales, una vez se disocia de su receptor de une a la proteína S logrando inactivar los factores de coagulación Va y VIIIa, además disminuye la apoptosis de células endoteliales y linfocitos e inhibe el PAI -1; en la sepsis es

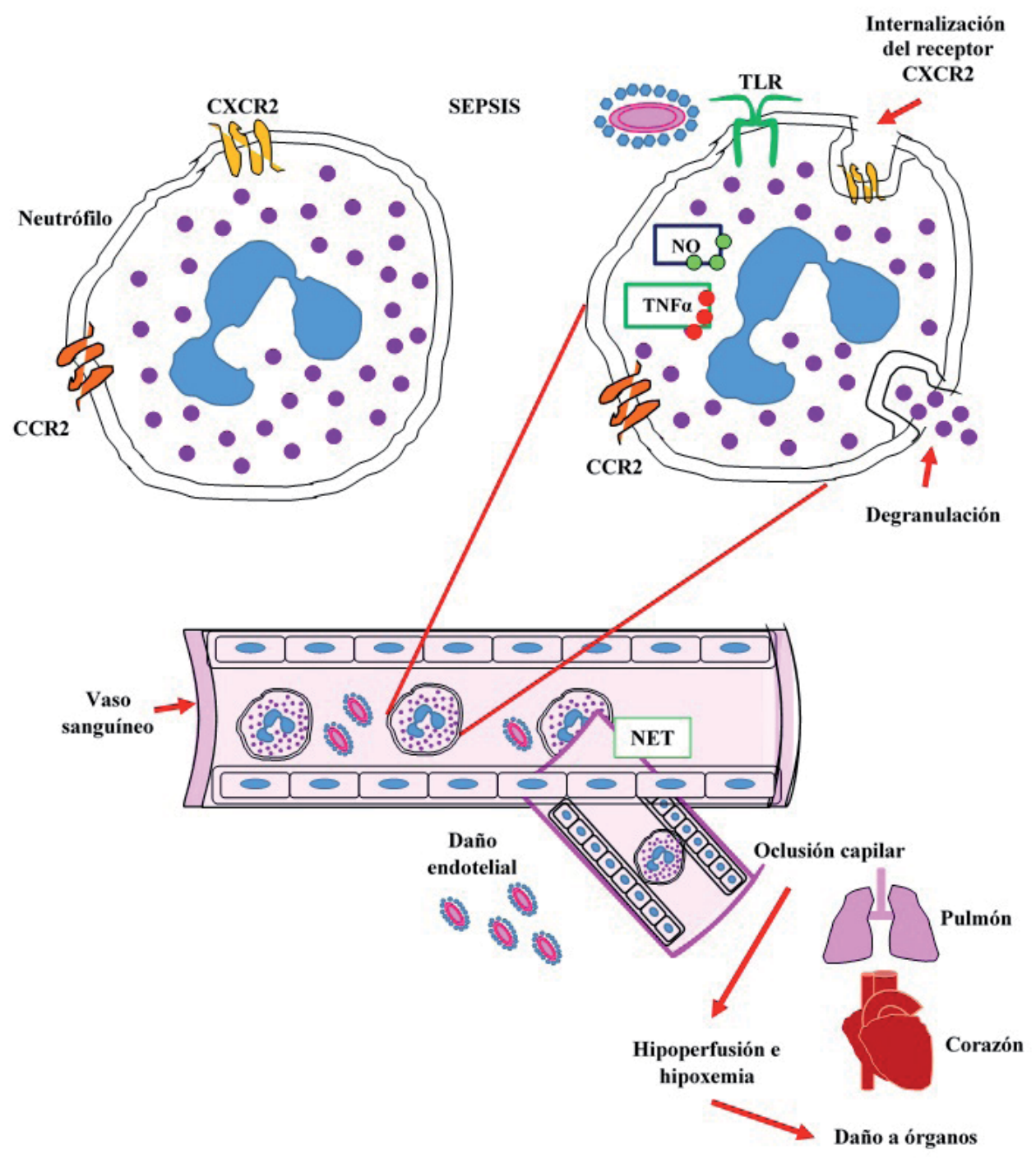

FIGURA 6. Neutrófilos en la fisiopatología y clínica de la sepsis.

Fuente: Construida por los autores con base en la hallada en el artículo: Sônego F, Castanheira FV, Ferreira RG, Kanashiro A, Leite CA, Nascimento DC, et al. Paradoxical Roles of the Neutrophil in Sepsis: Protective and Deleterious. Front Immunol. 2016;7(155):1-7. 
inhibida por la HMGB1 que interfiere en la unión de la trombina - trombomodulina. Otro evento de la coagulación que explica fenómenos de la sepsis es el hecho de que en las plaquetas activadas se expresa la $\mathrm{P}$-selectina luego de que han sido expuesta a la trombina y esto media la unión de los leucocitos a las células endoteliales y su activación contribuyendo a la lesión difusa de la microvasculatura que explica el daño orgánico ya mencionado $(11,52,53)$.

Durante la sepsis otro sistema que se ve fuertemente involucrado es el sistema de complemento que provee una línea importante de defensa del huésped al ayudar a contener y destruir los patógenos. En este sistema los patógenos son reconocidos por una de sus tres vías de activación, la de la clásica, la de la lectina, y la alternativa, las cuales llevan a una activación final de varios mecanismos, uno es la producción del C3 quien se encargará de la opsonización de las bacterias permitiendo su posterior fagocitosis; otro es la generación de las anafilotoxinas C3a, C4a y C5a, que aumentan la permeabilidad de los vasos sanguíneos, atraen leucocitos, C5a parece participar en el desarrollo de la parálisis inmunitaria, disfunción multiorgánica, apoptosis de células de la médula suprarrenal y desequilibrio en el sistema de la coagulación; y finalmente está el mecanismo del ensamblaje del complejo final $\mathrm{C} 5 \mathrm{~b}-9$ que lisara membranas bacteriana. El sistema de complemento y la coagulación interactúan y es por esto que encontramos como los productos finales del complemento, incrementan la trombogenicidad de la sangre al inducir la producción de procoagulantes y proteínas antifibrinolíticas así como la inhibición de anticoagulantes naturales, amplifica la coagulación mediante la modificación de los fosfolípidos de las membranas, mediante la activación de las plaquetas. Un ejemplo bien estudiado

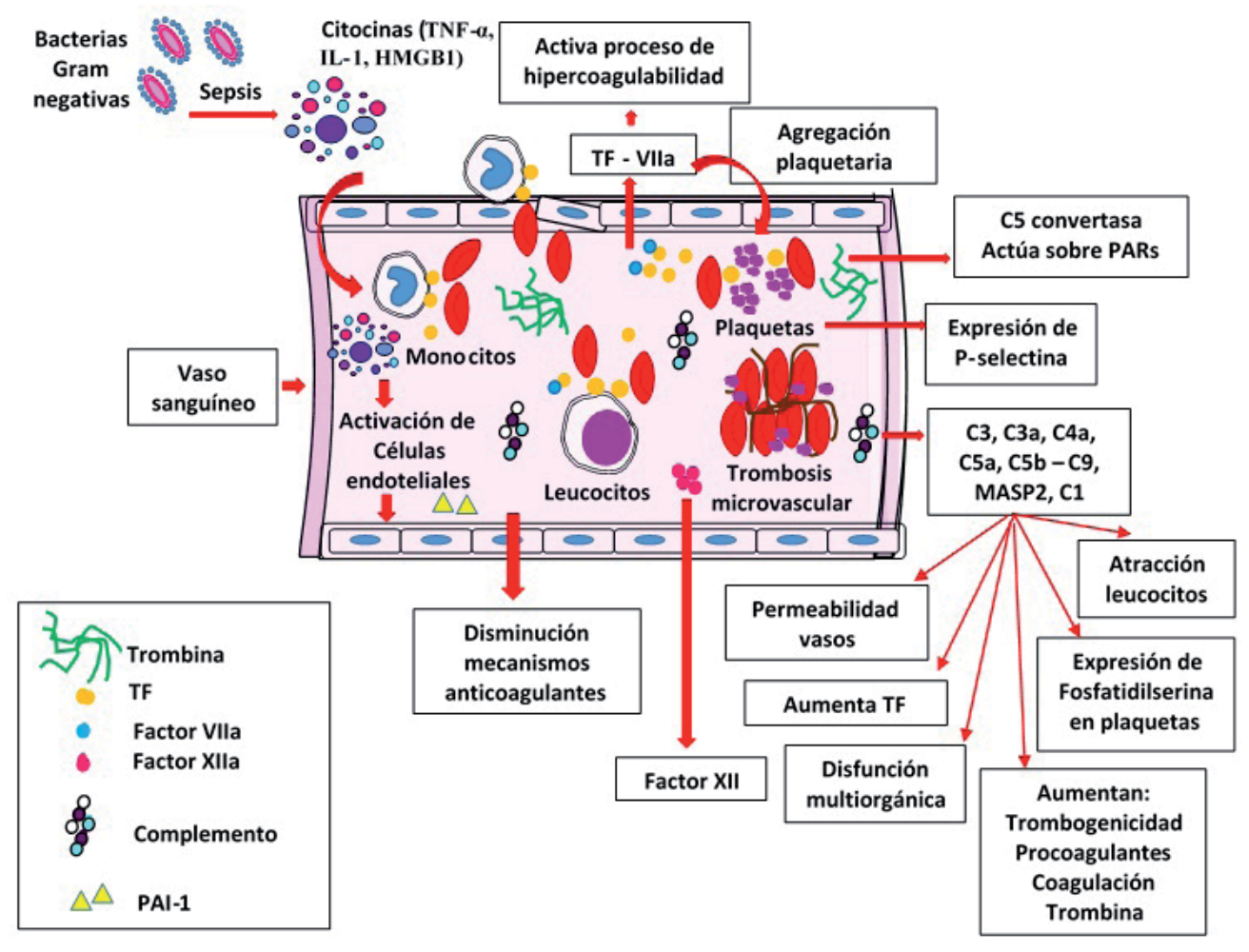

FIGURA 7. Integración de los Sistemas de Coagulación y Complemento en la Sepsis

Fuente: Construida por los autores con base en la hallada en el artículo: Allen KS, Sawheny E, Kinasewitz GT. Anticoagulant modulation of inflammation in severe sepsis. World J Crit Care Med. 2015 May 4;4(2):105-15; Lupu F, Keshari RS, Lambris JD, Coggeshall KM. Crosstalk between the coagulation and complement systems in sepsis. Thromb Res. 2014;133(01):S28-31. 
es el papel del complejo C $5 b-9$ que de manera específica puede inducir la producción del TF, inducir la fosfatidilserina en la superficie de las plaquetas ofreciendo una superficie catalítica para la agregación plaquetaria; otro ejemplo es el de la proteasa 2 de serina - lecitina unida a manan (MASP2) de la vía de la lectina que activa la coagulación al activar la trombina. De forma paralela en la interacción de estos dos sistemas se encuentra que ciertas enzimas de la coagulación como la trombina y el factor $\mathrm{Xa}$ activan componentes de la cascada del complemento, así, la trombina puede actuar como C5 convertasa independiente del C3, actúa sobre receptores específicos ubicados en las plaquetas, células endoteliales y leucocitos, llamados receptores con actividad de proteasa (PARs) que inducen la expresión del TF en las células y liberación del PAI - 1 que lleva a la inhibición de la fibrinólisis y disminución de la trombomodulina; el factor XIIa activa el componente $\mathrm{C} 1$ del complemento y la proteína $\mathrm{C}$ por su parte puede inhibir la activación del complemento (Figura 7) $(11,53,54)$.

\section{Conclusión}

Las bacterias gram negativas han sido las más vinculadas como agentes etiológicos de la sepsis, lo cual ha hecho que se avance en el estudio y la comprensión de su principal estructura antígenica, el Lipopolisacárico, y los mecanismos por los que desencadena la respuesta inmune que llevará a la liberación de las moléculas pro y anti inflamatorias que conducirán a los procesos orgánicos y sistémicos que dan lugar a la clínica del paciente séptico durante el curso de la enfermedad. Aunque sean diversas las moléculas antigénicas existentes en los distintos grupos de microorganismos, una vez desencadenada la respuesta inmune, los mediadores moleculares que explican la clínica del paciente, son básicamente los mismos, así que la comprensión de éstos y sus efectos permiten al médico y profesionales de la salud anticiparse en el manejo asertivo de la clínica del paciente.

\section{Referencias}

1. Singer M, Deutschman C, Warren C, Shankar-Hari M, Annane D, Bauer M, et al. The Third International Consensus Definitions for Sepsis and Septic Shock (Sepsis-3). JAMA. 2016; 315(8): 801810.

2. Ramachandran, G. Gram-positive and gram-negative bacterial toxins in sepsis A brief review. Virulence. 2014; 5(1): 213-218.

3. Rabirad N, Mohammadpoor M, Lari AR, Shojaie A, Bayat R, et al. Antimicrobial susceptibility patterns of the gram-negative bacteria isolated from septicemia in Children's Medical Center, Tehran, Iran. J Prev Med Hyg. 2014;55(1):23-6.

4. Pérez M, Sánchez J.J. Actualización de la Sepsis en Adultos. Código Sepsis [Internet]. Universidad Internacional de Andalucía. [20 Mayo 2016] 2014. Disponible en: http://dspace.unia.es/bitstream/handle/10334/3418/0607_P\%C3\%A9rez.pdf?sequence=3

5. Mak T, Brüggemann H. Vimentin in Bacterial Infections. Cells. 2016;5(2):1-8.

6. Do Vale A, Cabanes D, Sousa. Bacterial Toxins as Pathogen Weapons Against Phagocytes. Frontiers in MIcrobiology. 2016;7(42):1-21.

7. Adams P, Lamoureux L, Swingle L, Mukundan K, Montan G. Lipopolysaccharide-Induced Dynamic Lipid Membrane Reorganization: Tubules, Perforations, and Stacks. Biophysical Journal. 2014; 106:2395-2407.

8. Steimle A, Autenrieth I, Frick J.S. Structure and function: Lipid A modifications in commensals and pathogens. Int. J. Med. Microbiol. 2016; 306(5):290-301.

9. Harm S, Gabor F, Hartmann J. Low-dose polymyxin: an option for therapy of Gram-negative sepsis. Innate Immunity. 2016;22(4):274-283.

10. Band V, Weiss D. Mechanisms of Antimicrobial Peptide Resistance in Gram-Negative Bacteria. Antibiotics. 2015;4:18-41.

11. Carrillo R.C, Tapia J, Peña C.A, Kim Kohd M.J, Jaime A.R, Montalvo E. Bases moleculares de la sepsis. Revista de la Facultad de Medicina de la UNAM. 2014;57(3):1-13.

12. Castillo-Juárez I, Maeda T, Mandujano-Tinoco E, Tomás M, Pérez-Eretza B, García-Contreras S.J, et al. Role of quorum sensing in bacterial infections. World J Clin Cases. 2015;3(7):575-598.

13. March Rossello' a G.A, Eiros Bouza J.M. Quorum sensing en bacterias y levaduras. Med Clin (Barc). 2013;141(8):353-357.

14. Reuter K, Steinbach A, Helms V. Interfering with Bacterial Quorum Sensing. Perspectives in Medicinal Chemistry 2016;8:1-15.

15. Prieto A, Urcola I, Blanco J, Dahbi G, Muniesa M, Quirós P, et al. Tracking bacterial virulence: global modulators as indicators. Scientific Reports. 2016;6(25973):1-11.

16. Yamamoto H, Oda M, Kanno M, Tamashiro S, Tamura I, Yoneda T, et al. Chemical Hybridization of Vizantin and Lipid A to Generate a Novel LPS Antagonist. Chem. Pharm. Bull. 2016;64:246257.

17. Oda M, Yamamoto H, Shibutani M, Nakano M, Yabiku K, Tarui T, et al. Vizantin Inhibits Endotoxin-Mediated Immune Responses via the TLR 4/MD-2 Complex. J Immunol. 2014;193:45074514.

18. Martinez de Tejada G, Heinbockel L, Ferrer-Espada R, Heine $\mathrm{H}$, Alexander C, Bárcena-Varela S, et al. Lipoproteins/peptides are sepsisinducing toxins from bacteria that can be neutralized by synthetic anti-endotoxin peptides. Scientific Reports. 2015;5(14292):1-15.

19. Chang Y, Tsai M, Huey-Herng Sheu W, Hsieh S, Chiang A. The Therapeutic Potential and Mechanisms of Action of Quercetin in Relation to Lipopolysaccharide-Induced Sepsis In Vitro and In Vivo. PLOS ONE. November 2013;8(11):1-13. 
20. Takashima K, Matsushima M, Hashimoto K, Nose H, Sato M, Hashimoto N, et al. Protective effects of intratracheally administered quercetin on lipopolysaccharide-induced acute lung injury. Takashima et al. Respiratory Research 2014;15(150):1-10.

21. Chen K.F, Chaou C.H, Jiang J.Y, Yu H.W, Meng Y.H, Tang W.C, et al. Diagnostic Accuracy of Lipopolysaccharide-Binding Protein as Biomarker for Sepsis inAdult Patients: A Systematic Review and Meta-Analysis. PLOS ONE. 2016;11(4):1-13.

22. Krasity B, Troll J, Lehnert E, Hackett K, Dillard J, Apicella M, et al. Structural and Functional Features of a Developmentally Regulated Lipopolysaccharide-Binding Protein. mBio. 2015;6(5):110 .

23. Dupont A, Heinbockel L, Brandenburg K, Hornef M. Antimicrobial peptides and the enteric mucus layer act in concert to protect the intestinal mucosa. Gut Microbes Deecember 2014;5(6):761765 .

24. Fang L, Xu Z, Wang G.S, Ji F, Mei C, Liu J, et al. Directed Evolution of an LBP/CD14 Inhibitory Peptide and Its Anti-Endotoxin Activity. PLoS One. 2014;9(7):1-10.

25. Płóciennikowska A, Hromada-Judycka A, Borzecka K, Kwiatkowska K. Co-operation of TLR4 and raft proteins in LPSinduced pro-inflammatory signaling. Cell. Mol. Life Sci. 2015;72:557-581.

26. Yang H, Wang H, Ju Z, Ragab A.A, Lundbäck P, Long W. MD-2 is required for disulfide HMGB1- dependent TLR4 signaling. J Exp Med. 2015;212(1):5-14

27. Wang H, Wei Y, Zeng Y, Qin Y, Xiong B, Qin G, et al. The association of polymorphisms of TLR4 and CD14 genes with susceptibility to sepsis in a Chinese population. BMC Med Genet. 2014;15(123):1-9.

28. Mukherjee S, Karmakar S, Sinha Babu S.P. TLR2 and TLR4 mediated host immune responses in major infectious diseases: a review. braz j infect dis. 2016; 20(2):193-204.

29. Paramo T, Tomasio S.M, Irvine K.L, Bryant C.E, Bond P.J. Energetics of Endotoxin Recognition in the Toll-Like Receptor 4 Innate Immune Response. Sci Rep. 2015;5(17997):1-13.

30. Zhang S, Yu M, Guo Q, Li1 R, Li G, Tan S, et al. Annexin A2 binds to endosomes and negatively regulates TLR4- triggered inflammatory responses via the TRAM-TRIF pathway. Sci Rep. 2015;5(15859):1-15.

31. Tsirigotis P, Chondropoulos S, Gkirkas K, Meletiadis J, Dimopoulou I. Balanced control of both hyper and hypo-inflammatory phases as a new treatment paradigm in sepsis. J Thorac Dis. 2016;8(5):E312-E316.

32. Boomer JS, Green JM, Hotchkiss RS. The changing immune system in sepsis: is individualized immuno-modulatory therapy the answer?. Virulence. 2014;5(1):45-56.

33. Kajiwara Y, Schiff T, Voloudakis G, Gama Sosa M.A, Elder G, Bozdagi O, et al. A Critical Role for Human Caspase-4 in Endotoxin Sensitivity. J Immunol. 2014;193(1):335-43.

34. Smith C, Wang X, Yin H. Caspases come together over LPS. Trends Immunol. 2015;36(2):59-61.
35. Aziz, Jacob A, Wang P. Revisiting caspases in sepsis. Cell Death Dis. 2014;20(5):1-12.

36. Jorgensen I, Miao E.A. Pyroptotic cell death defends against intracellular pathogens. Immunol Rev. 2015;265(1):130-142.

37. Wiersinga W.J, Leopold S.J, Cranendonk D.R, Van der Poll T. Host innate immune responses to sepsis. Virulence. 2014;5(1):36-44.

38. ManS.M, Kanneganti T.D. Regulation of inflammasome activation. Immunol Rev. 2015;265(1):6-21.

39. Suárez R, Buelvas N. El inflamosoma: mecanismos de activación. Invest Clin. 2015;56(1):74 - 99.

40. Gómez H.G, Rugeles M.T, Jaimes F.A. Características inmunológicas claves en la fisiopatología de la sepsis Infectio. 2015;19(1):40-46.

41. Yu Y, Tang D, Kang R. Oxidative stress-mediated HMGB1 biology. Front Physiol. 2015;6:93:1-9.

42. Wang H, Ward MF, Sama AE. Targeting HMGB1 in the treatment of sepsis. Expert Opin Ther Targets. 2014;18(3):257-68.

43. Lee SA, Kwak MS, Kim S, Shin JS. The role of high mobility group box 1 in innate immunity. Yonsei Med J. 2014;55(5):116576.

44. Luo L, Zhang S, Wang Y, Rahman M, Syk I, Zhang E, Thorlacius $H$. Proinflammatory role of neutrophil extracellular traps in abdominal sepsis. Am J Physiol Lung Cell Mol Physiol. 2014;307(7):L586-96.

45. Zhang J, Yang J, Xu X, Liang L, Sun H, Liu G, et al. The influence of genetic polymorphisms in TLR4 and TIRAP, and their expression levels in peripheral blood, on susceptibility to sepsis. Exp Ther Med. 2016;11(1):131-139.

46. Bataille A, Galichon P, Ziliotis MJ, Sadia I, Hertig A. Epigenetic changes during sepsis: on your marks!. Crit Care. 2015;19(358):1-3.

47. Arens C, Bajwa SA, Koch C, Siegler BH, Schneck E, Hecker A, et al. Sepsis-induced long-term immune paralysis - results of a descriptive, explorative study. Crit Care. 2016;20(93)1-11

48. Schulte W1, Bernhagen J, Bucala R. Cytokines in sepsis: potent immunoregulators and potential therapeutic targets--an updated view. Mediators Inflamm. 2013;2013(165974):1-16.

49. Yan J, Li S, Li S. The role of the liver in sepsis. . Int Rev Immunol. 2014;33(6):498-510.

50. Minemura M, Tajiri K, Shimizu Y. Liver involvement in systemic infection. World J Hepatol. 2014;6(9):632-42.

51. Sônego F, Castanheira FV, Ferreira RG, Kanashiro A, Leite CA, Nascimento DC, et al. Paradoxical Roles of the Neutrophil in Sepsis: Protective and Deleterious. Front Immunol. 2016;7(155):1-7.

52. Allen KS, Sawheny E, Kinasewitz GT. Anticoagulant modulation of inflammation in severe sepsis. World J Crit Care Med. 2015 May 4;4(2):105-15.

53. Lupu F, Keshari RS, Lambris JD, Coggeshall KM. Crosstalk between the coagulation and complement systems in sepsis. Thromb Res. 2014;133(01):S28-31.

54. Charchaflieh J, Rushbrook J, Worah S, Zhang M. Activated Complement Factors as Disease Markers for Sepsis. Dis Markers. 2015;2015(382463):1-9. 